\title{
تأثير تدريبات الكروس فيت علي بعض القدرات البدنية و المستوي الرقمي لسباحي الزعانف
}

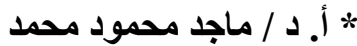

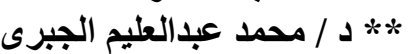

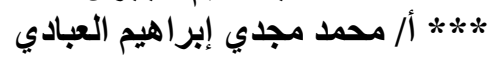

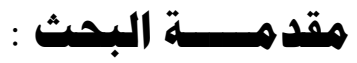

يسعي التنريب الرياضي الي تطوير ونوجيه القوة البدنية والفنية للفرد الرياضي نحو تحقيق

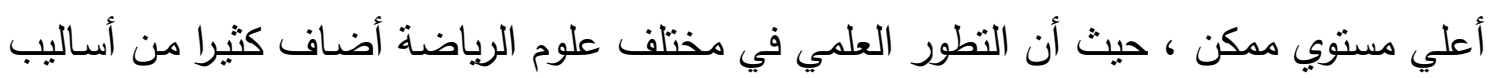

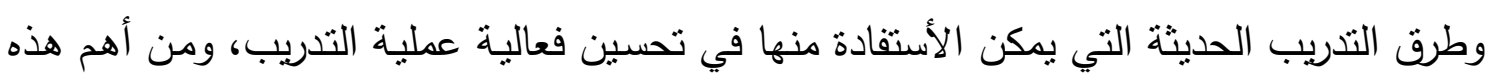
الطرق الحديثة الكروس فيت وإستخدامة في تتمية القوة العضلية والسرعة وبعض القدرات البدنية الخاصـة ليس في سباحة الزعانف فقط ولكن في مختلف الرياضـات، حيث أن الإعداد البدني للسباحين عامة وسباحي الزعانف خاصة أصبح من أهم الوسائل لتحسين المستوي الرقمي، وخاصة في ظل إستخدام البعض لتدريبات القوة التقليدية التي بدأت تصيب السباحين بالملل وكونت لدي بعض منهم كراهية شديدة للنتريب الأرضي مما دفع بعض الناشئين في المراحل العمرية المختلفة لأهمال التدريب الأرضي وعدم رغبنهم في تحقيق أزمنة قياسية، كما دفعت البعض الأخر لنرك لته رياضية السباحة والأتجاه لصالات الأثقال من أجل الضخامة العضلية والحصول علي جسم ينسم بالقوة وبأستخدام وسائل غير أمنة كالهرمونات وتحت إثراف مدربين غير متخصصين، لذا كان من الضروري إيجاد طريقة علميـة وأمنـة لزيادة القوة العضلية والقدرات البدنية الخاصـة بسباحة الزعانف وفي نفس الوقت قادرة علي جذب السباحين علي التدريب الأرضي فأصبح السباحين الممارسين للكروس فيت يمارسون رياضتين في أن واحد وفي نفس الوقت يجدون الجسم المتميز الذين يريدون الحصول عليه وتحقيق الأزمنة القياسية والوصول للأنجاز . ويعرف "تيكولاس موراي" (2019م) "NicholasMurray" أن الكروس فيت هي رياضة تجمع بين جوانب متعددة من اللياقة الهوائية واللاهوائية،منل تدريب المقاومة،تدريب القلب والأوعية الدموية ، وحركات الجمبازوكلها تمارين مصممة لتحسين اللياقة العامة للأفراد. (3.20 ) 
ويعرف أحمد عوض حسن (2019) وأخرون أن الكروس فيت طريقة معاصرة لتدريب القدرات البدنيـة من خـلال تعزيز اللياقـة البدنية بشكل عام من تطوير القدرات الهوائيـة والتحمل

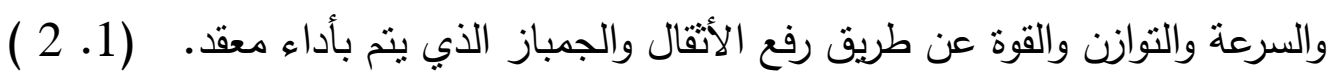
ويري "قابيو دمونسكي وأخرون " Fàbio Dominski" \&ather" (2020) أن لاعبي الكروس فيت يتميزو عن مختلف الرياضـيون وذلك في المهارات الجسـية والعوامل المتعلقـة بالصحة إضافة إلي ذلك الاستمتاع والتحدي في المنافسة. ( 7.19 ) ويشيركل من "مورتيزشومان" و" وينتررونستاد" (2019) Mortiz \& Bent r "' إلي أهمية تدريبات القوة للسباحين لتحقيق النجاح التنافسي علي المستوي الدولي والمحلي ويجب أن تتمل البرامج الخاصـة بهم علي تدريبات المقاومـة طوال العـام امـا للمحافظـة علي القوة أوزيادتهـا أو لتحسين أنماط الحركة والحد من خطر الأصابة. (5.21) ويري"أشرف محمد جمعة" (2019) أن عدم كفاية القوة العضلية يؤثر سلباعلي مستوي إتقان وتطوير الأداء المهاري في السباحة حيث أن جسم السباح يتحرك للأمام عن طريق محصلة القوة الناتجة عن حركات الذراعين وضربات الرجلين متخذا الوضع الأفقي داخل الماعلذلك فأن أداءالمهارات الخاصة بالسباحة ينطلب حد أقصي من القوة العضلية ـ (52.2 ) ويري الباحث من خلال خبراته في مجال تدريب اللياقة البدنية في القرية الأوليمبية جامعة

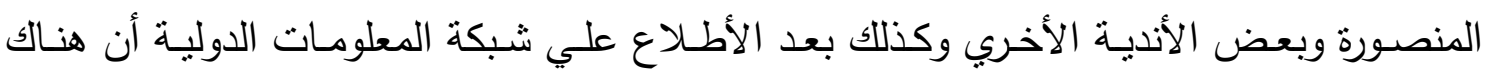
اهمال في التدريب الأرضي وعدم الأهتمام بتدريبات القوة العضلية سواء بأستخدام وسائل حديثة مثل الكروس فيت أو التدريبات التقليديـة، ومن خـلال المقابلة الثخصية لبعض مدربي السباحة للناشئين واطلاع الباحث علي البرامج التدريية المختلفة لناشئي السباحة تبين لهما أنها تقتقر إلي التذريبات الخاصة بالقوة العضلية بالسباحة والاعتماد علي التدريب المائي بصورة أساسية . ولذا فإن هذا البحث يعتبر محاولة علميـة لتطوير وتوجيه تدريبات القوة وبعض القدرات البدنية الخاصة علي المستوي الرقمي لسباحي الزعانف.

يهدف البحث إلي التعرف علي " تأثير تدريبات الكروس فيت علي بعض القدرات البدنية والمستوي الرقمي لسباحي الزعانف" . 
1. توجد فروق دالة إحصائيًاً بين القياسين (القبلي - البعدي) للمجموعة التجريبية في

$$
\text { القدات البننية والمستوي الرقمي لصالح القياس البعدي. }
$$

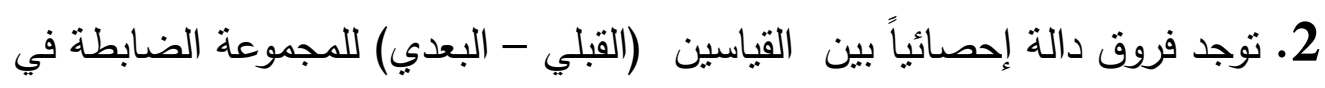

$$
\text { القدرات البننية والمستوي الرقمي لصالح القياس البعدي. }
$$

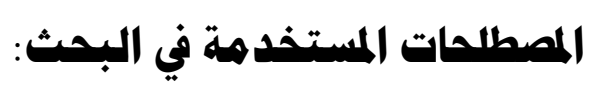

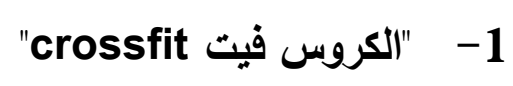

هو إتجاه وظيفي يسعي للحد من الأداء البشري لعدد من الحركات البسيطة والتي لايمكن

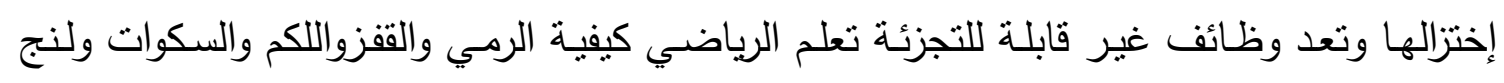

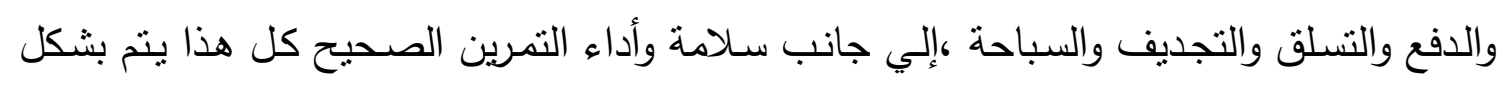

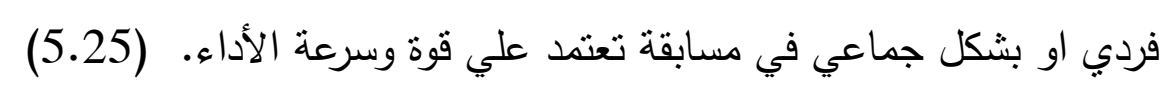

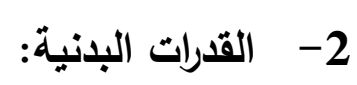

هي عبارة عن مقدرة الجسم علي الاحتفاظ بمستوي ثابت في إستمرار الأداء وتحمل العبء

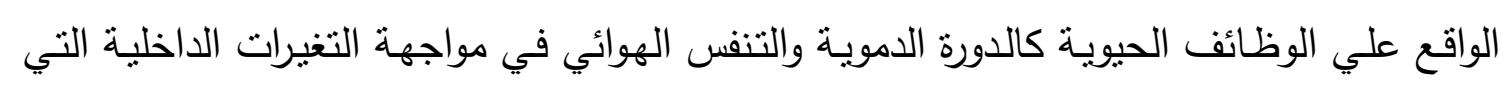
نظهر نتيجة العمل البني. (12.6) 3- 3ستوي الانجاز الرقمي في السباحة:

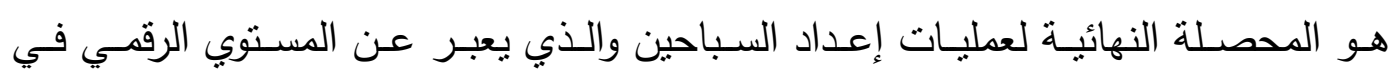

$$
\begin{aligned}
& \text { السباقات ويقاس بالزمن. (15،6) } \\
& \text { 4- ن ناشئ سباحة الزعانف: }
\end{aligned}
$$

هو الناشئ الذي يمارس سباحة الزعانف بدءا من 11 عام أو أقل مرحلة (E) ويطلق عليها

$$
\begin{aligned}
& \text { (مرحلة ماقبل المنافسة) حتي المرحلة(B) من } 16 \text { - } 17 \text { عام. } \\
& \text { 5- سباحة الزعانف : }
\end{aligned}
$$

هي تطور الزعانف المونو أو الزعانف المزدوجة سواء في مسابقات السطح أوفي مسابقات

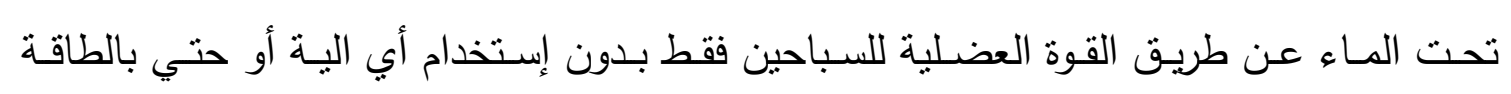

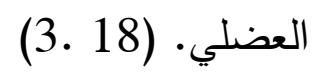


- الكروس فيت والاعداد البذني في سباحة الزعانف:

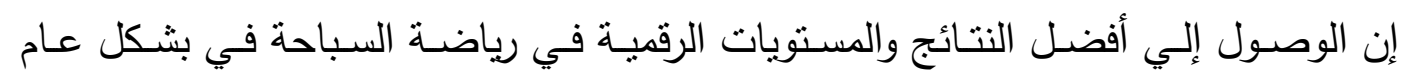

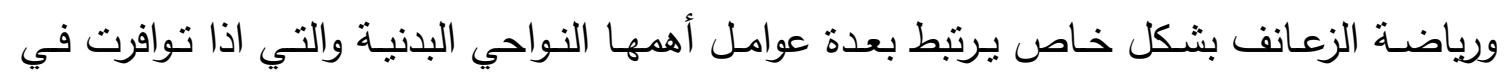

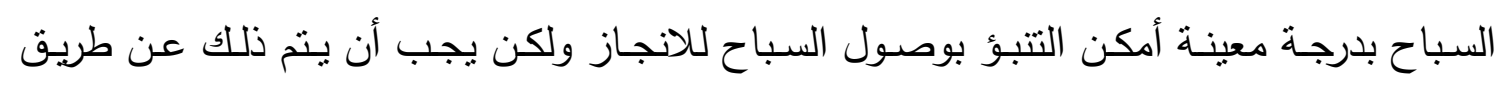
الكروس فيت حيث أنه يلبي متطلبات السباحين في كافة النواحي البننية والوظيفية لما يحنوية من لن تتوع في تمـارين الأثقال والسرعة والمرونة والجمباز والتحمل الدوري التتفسي كلها داخل الوحدة التدريبة الواحدة مما يوفر القدرات البدنية الخاصة الخاصة والضرورية للنشاط الممارس. ويذكر"مصطفي سمير(2018) وأخرون أن الاعداد البدني أهم أركان التدريب التي بعتمد

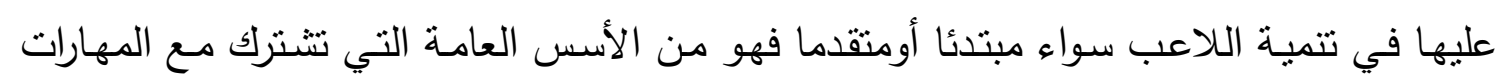

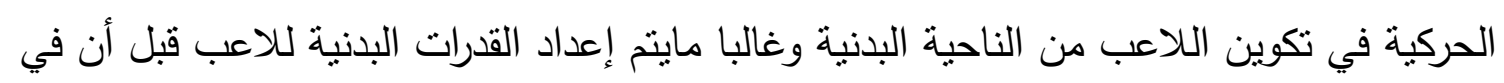

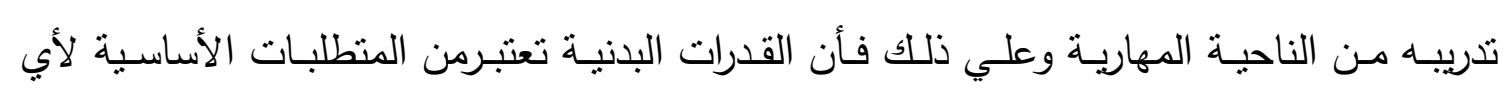

رياضة. (5.14 )

Nicholas Murray (2019) ويتفق كل من "أحمد عوض ، نيكولاس مواري ، جلاسمان

\&lassman

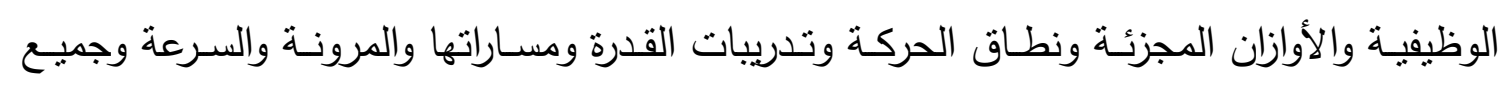

عمليات الأيض ذات الصلة في قيمة واحدة لذا فأن الكروس فيت رياضة اللياقة البدنية ـ (5.1) ويذكر"محمد محمود عبد التواب"(2016) نقلا عن "وائل حنفي" أن سباحة الزعانف تعتبر أحد أهم أنواع الرياضات التي أعيد تتظيمها حديثا بالرغم من قدم نشأتها حيث أرتطبت برياضـة

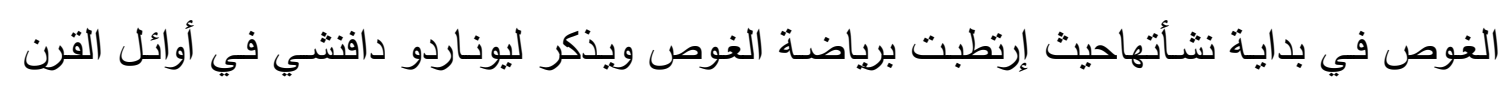

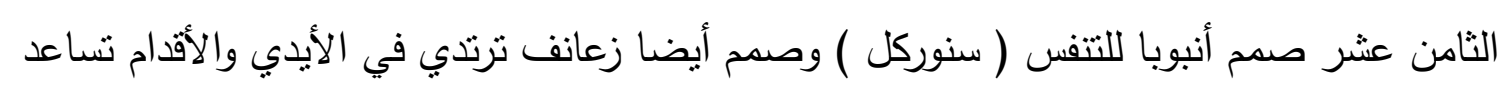
الغواص علي السرعة العالية.

فقد أجريت اول بطولـة رسمية في سويسـرا عـام ( 1967) وقد تم تحسبن أداء الزعانف التقليدية المصنوعة من المطاط وقد إستخدم السباحون نوعاما من الزعانف ذات النصال المصنوعة من رقائق الصلب وفي أول السبعينيات نم ظهور زعانف الزعانف المصنوعة من الألباف الزجاجية 
وذلك في بطولة برشلونة والذي إستخدمها السباحون الروس لأول مرة وقد تبنت جميع الدول هذا النوع من الزعانف واشـاد بـه جميع السباحين لخفته ومرونته وقلة إجهاد الجهاز العصبي وظهرت زعانف المونو والتي غيرت التصور تماما في سباحة الزعانف وقد تكيف السباحون مع هذا التكنيك الجديد للسباحة بالزعانف. (3.12 )

\section{القدرات البدنية في السباحة :}

-

تعتبر القوة العضلية من أهم عناصر اللياقة البدنية اللازمـة لممارسة الأنشطة البننية

عامة وكذلك التفوق فيها وكذلك للوصول إلى المستويات العالية، وقد تكون من أهم العناصر على لهى الإطلاق فى الأداء الرياضى. (176:3)

وتعرفها نورا أبو المعاطي (2012) وأخرون بأنها مقدرة العضلات على إنتاج أقصى

انقباض عضلى إرادى لعدد محدد مـن التكرارات أو لفترة زمنيـة محددة وفقا لمنطلبـات النشـاط الرياضى الممارس. (55:16)

ويذكر مصطفي سـمير(Maglischo أن هناك ثناث مبادئ أساسية

لتتمية القوة العضلية لدي السباحين وهي:

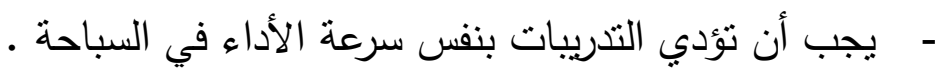

- - يجب أن تتثابه طريقة أداء التمرينات مع طرق الأداء في السباحة بقدر الإمكان.

- يجب التدرج في زيادة المقاومة. (7.14 )

- - السرعة Speed (مفهومها ، أشكالها)

يؤكد أبـو العـلا عبد الفتـاح وحـازم حسين سـالم (2011) ان السرعة تعتبر في المجال

الرياضي من القدرات البدنية الأساسية والهامة التي تلعب دورا في تحسين وتقدم مستوي الكثير من الرياضين مختلف الالعاب الفردية والجماعية فأغاليية هذه الالعاب تعتمد علي السرعة كعنصر أساسي فيها عند أداء المهارات المختلفة. ( 4. 148) ويري عويس الجبالي (2001) أن السرعة تمثل إحدي القدرات البدنية الهامسة والمنطلب الضروري لمعظم الأنشطة الرياضية ، حيث تساعد الرياضي علي الاداء بأقصي سرعة. (432.10) 
ويذكر أبو العلا عبد الفتاح(1994) أنه عند تتمية السرعة يجب تتمية كلا من :

$$
\text { - ت تمية سرعة رد الفعل. }
$$

-

- ت تمية السرعة القصوي للتردد الحركي " سرعة حركة الرجلين والذراعين"

ويستخدم لتحقيق ذلك تدريبات خاصة لتتمية مكونات السرعة المختلفة في شكل يتلائم مع

منطلبات تتفيذ السباق. (141.5)

Flexibility المرونة -

ويذكر محمــ شـوقى كثــك وأمسر الله البسـاطى 2001م أن المرونـة تعنى المدى الحركى المى

لمفصل أو مجموعة من المفاصل، وتقاس المرونة بأقصى مدى بين بسط وقبض المفصل، ويعبر عن ذللك إما بدرجة الزاوية أو بخط يقاس بالسنتيمترات، وهى تعنى قدرة اللاعب على تحريك جسمه أو جزء من أجزائه خلال مدى حركى واسع دون توتر مفرط غير مناسب للمفاصل والعضلات. $(80: 13)$

\section{الدراسات المرجعيهة:}

1 - وجدان سامي عبد الحميد محمد (2019)

" نأثير ندريبات الكروس فيت علي الكفاءة البدنية والمستوي الرقمي لسباحي 400مثر حرة "

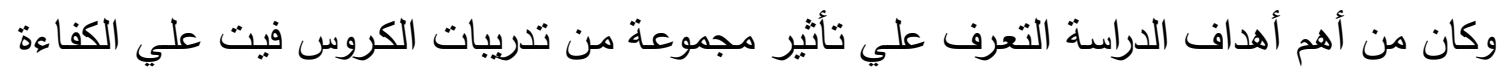
البدنية والمستوي الرقمي لسباحي 400متر حرة وقد إستخدمت الباحثة المنهج التجريبي بأستخدام

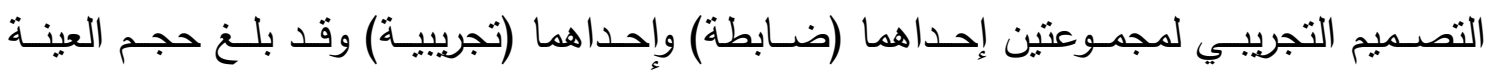
(20سباح) وقد اثنارة النتائج تفوق المجموعة التجريبية التي إستخدمت تدريبات الكروس فيت عن إندان المجموعة التي إستخدمت التدريبات العادية. (17)

\section{2- 2019) أثرف محمد جمعة (2019)}

" نأثير بعض تدريبات القوة العضلية علي المستوي الرقمي لسباحي الزعانف" وكان من أهم

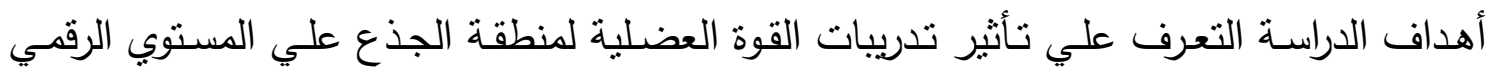
لسباحي الزعانف وقد إستخدم الباحث المنهج التتجريبي بأستخدام التصميم التجريبي لمجموعتيني

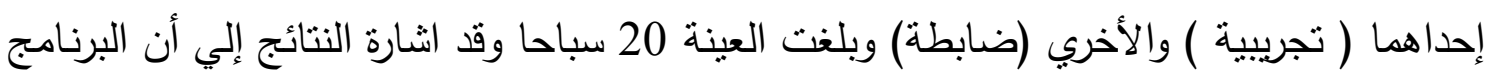


التدريبي المقترح بأستخدام تدريبات القوة العضلية كان له تأثيرا إيجابيا في تطويروتحسين المستوي الرقمي لسباحي الزعانف. (2)

3- مصطفي عبد الناصر حسين أبو الليل (2016)

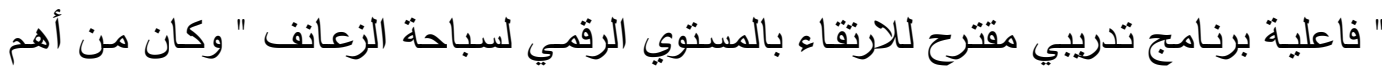

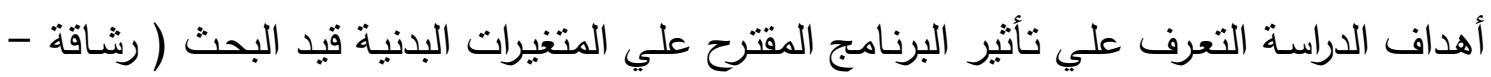

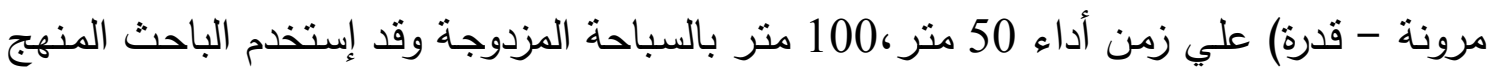

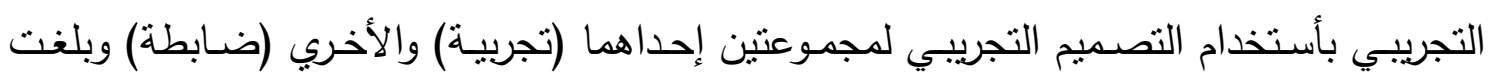

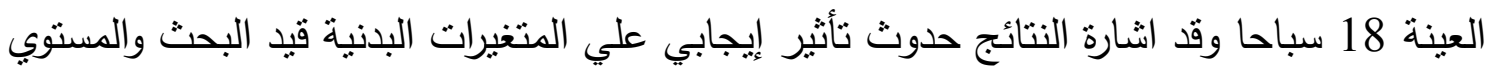
الرقمي لسباحة الزعانف. (15)

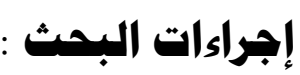

إسـتخدم الباحث المنهج التجريبـي بإتبـاع التصـيميم التجريبـي ذو القيـاس القبلـي والبعدي لمجموعة تجريبية ومجموعة ضابطة وذللك لملائمته طبيعة هذا البحث.

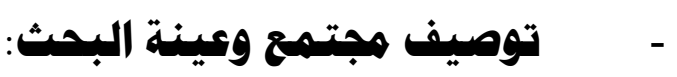

جدول ( 1 )

توصيف عينة البحث.

\begin{tabular}{|c|c|c|c|c|}
\hline \multirow{2}{*}{ البرنامج } & \multicolumn{3}{|c|}{ العينة } & \multirow[b]{2}{*}{ b } \\
\hline & النسبة & العدد & نوع العينة & \\
\hline المقترح & \%40.00 & 10 & المجموعة التجريبية & 1 \\
\hline المتبع & $\% 40.00$ & 10 & المجموعة الضابطة & 2 \\
\hline- & $\% 20.00$ & 5 & المجموعة الاستطلاعية & 3 \\
\hline - & $\% 100$ & 25 & العينة الكلية للبحث & \\
\hline
\end{tabular}

1. أن يكون اللاعب من ناشئي القرية الأوليمييية جامعة المنصورة.

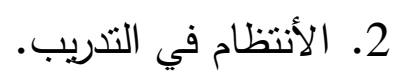
3. أن ينضم اللاعبين لتجربة البحث بموافقة ولي الأمر. شروط إختيار العينة - ان يكون السباح قد شارك فى بطولات الجمهورية خلال العامين السابقين. 
- يتم تدريب العينه داخل النادى تحت نفس الظروف وتحت رعايه الباحث.

- - موافقه افراد العينة على المشاركة فى اجراء القياسات خلال مرحله المنافسات.

- الانتظام فى التدريب مرحلة الاعداد العام والخاص السابقين.

تجانس وتكافؤ عينة البحث:

قام الباحث بإجراء التجانس والتكافؤ بين مجموعتي البحث ( التجريبية - الضـابطة) في

المتغيرات قيد البحث كما هو موضح في الجدول ( 2 ) ، ( 1 ) :

جدول ( 2 ( )

المتوسطات الحسابية والوسيط والانحرافات المعيارية ومعاملات الالتواء للعينة الكلية للبحث في

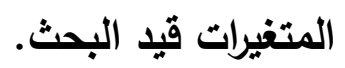

$(25=\dot{0})$

\begin{tabular}{|c|c|c|c|c|c|c|}
\hline 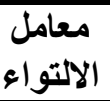 & المعياري & 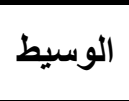 & المستوسط & 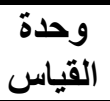 & المتفيرات & p \\
\hline 2.65 & 0.51 & 16.00 & 16.45 & سنة & السن & $\overline{11}$ \\
\hline 0.00 & 3.80 & 178.00 & 178.00 & سم & الطول & 2 \\
\hline $0.16-$ & 3.65 & 74.00 & 73.80 & كجم & 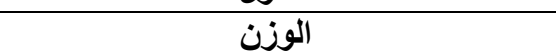 & 3 \\
\hline 0.67 & 0.89 & 3.00 & 3.20 & سنة & العمر التدريبي & 4 \\
\hline 0.23 & 1.95 & 9.00 & 9.15 & سم & مرونة العمود الفقري في اتجاه الدد & 5 \\
\hline 0.71 & 2.31 & 240.50 & 241.05 & سم & القلقرة العضلية الوثب العريض من الوقوف & 6 \\
\hline 0.88 & 0.41 & 3.55 & 3.67 & ث & السر عة القصوي عدو 30متر & 7 \\
\hline 0.06 & 2.52 & 16.00 & 16.05 & عدد & القوة العضلية للأراعين & 8 \\
\hline 0.12 & 3.77 & 43.50 & 43.65 & عدد & القوة العضلية للبطن & 9 \\
\hline 2.45 & 2.45 & 20.00 & 22.00 & كجم & قوة عضلات الطرف العلوي (1rmess press) & $\begin{array}{l}1 \\
0\end{array}$ \\
\hline $0.80-$ & 3.74 & 30.00 & 29.00 & كجم & قوة عضلات الطرف السفلي (1rm) سكوات & 1 \\
\hline 0.40 & 1.74 & 51.23 & 51.46 & 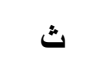 & المستوي الرقمي 100م زعانف & 1 \\
\hline
\end{tabular}

يتضح من جدول( 2 ) أن قيم معاملات الالتواء انحصرت ما بين (-3) و (+3) مما يدل

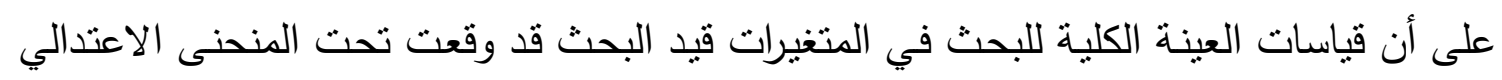
وهذا يدل على تجانس أفراد عينة البحث الكلية في هذه المتغيرات.

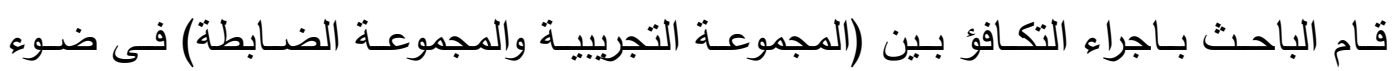

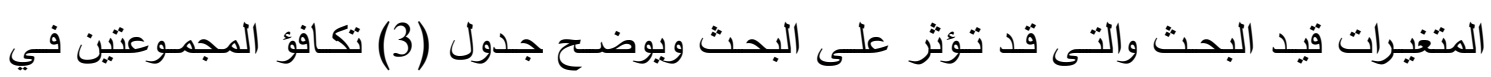

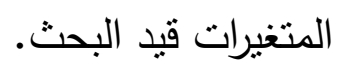




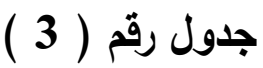

تكافؤ مجموعتي البحث (التجربية- الضابطة) في الاختبارات قيد البحث

$(10=2 ن=1$ ن

\begin{tabular}{|c|c|c|c|c|c|c|c|}
\hline \multirow{2}{*}{ قتمة } & \multicolumn{2}{|c|}{ المجموعة الضابطة } & \multicolumn{2}{|c|}{ المجموعة التجريبية } & \multirow{2}{*}{ وحدة القياس } & \multirow[b]{2}{*}{ المتغيرات } & \multirow[b]{2}{*}{ p } \\
\hline & $\begin{array}{l}\text { الانحراف } \\
\text { ( } 1 \pm \text { ) }\end{array}$ & المتوسَ) & 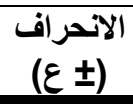 & المتوسن) & & & \\
\hline 0.11 & 2.13 & 9.10 & 1.87 & 9.20 & سم & مرونة العمود الفقري في اتجاه المد & 1 \\
\hline 0.09 & 2.49 & 16.00 & 2.69 & 16.10 & عدد & القوة العضلية للأراعين & 2 \\
\hline 0.06 & 4.16 & 43.70 & 3.57 & 43.60 & عداد & القوة العضلية للبطن & 3 \\
\hline 1.73 & 2.69 & 241.90 & 1.55 & 240.20 & 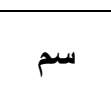 & القدرة العضلية الوثب العريض من & 4 \\
\hline 0.06 & 0.34 & 3.68 & 0.49 & 3.67 & $\dot{4}$ & السرعة عدو 30متر & 5 \\
\hline 1.33 & 1.70 & 20.70 & 2.58 & 22.00 & 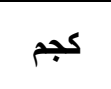 & قوة عضلات الطرف الطوي (1rm) & 6 \\
\hline 0.63 & 4.61 & 27.80 & 3.94 & 29.00 & كجم & قوة عضلات الطرف السفلي (1rm) & 7 \\
\hline 0.14 & 1.63 & 51.41 & 1.93 & 51.52 & $\dot{4}$ & المستوي الرقمي 100متر زعانف & 8 \\
\hline
\end{tabular}

تج (18) $2.10=0.05$

يتضح من جدول ( 3 ) عدم وجود فروق ذات دلالة إحصـائية بين القياسات قيد البحث

للمجموعتين التجريبيتين حيث كانت قيمـة (ت) المحسوبة أقل من قيمتها الجدولية عند مستوى

معنوية (0.05)، مما يدل على عدم وجود فروق دالة إحصائية بين القياسات في جميع الاختبارات،

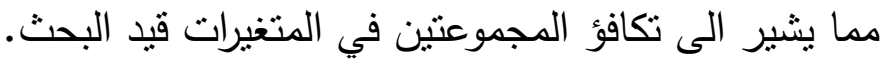

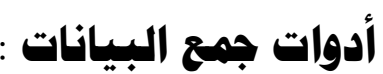

الادوات والاجهزة المستخدهه فى القياس

- - جهاز الرستاميتر لقياس الطول ، وحدة القياس السنتيمتز • - جهاز الميزان الطبي لقياس الوزن ، وحدة القياس الكيلوجرام.

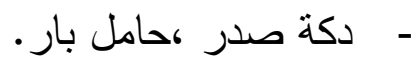

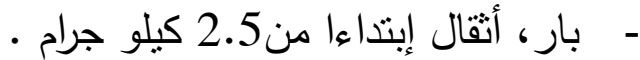

- - ماعة إيقاف لأقرب 100/1 من الثانية.

خطوات تنفيذ البحث

قام الباحث باتباع الخطوات التنفيذية للبحث كالأتي : 


\section{الخطوات التخضيرية :}

- الحصول علي موافقة مدير القرية الأوليمبية جامعة المنصورة علي الدراسة قيد البحث علي

سباحي الزعانف بقطاع الناشئين حيث أن الباحث المعد البدني الخاص بقطاع النانشئين . - تم أخذ مواقفة أولياء الأمسور علي تطبيق الدراسـة قيد البحث فوإجراءات القياسـات علي

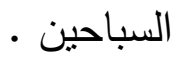
- - إختيار وتدريب المساعدين وتوصيف طبيعة عمهم داخل البحث.

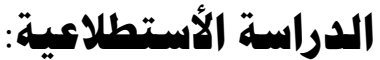

تم إجراء هذه الدراسة في الفترة من الثلاثاء (3/ 9 /2019) إلي الثناثاء الموافق (10/1) /2019) علي مجموعة من(5) سباحين من نادي جزيرة الورد بالمنصورة. - 2 - مدف الدراسة:

1. تصميم إستمارة تسجيل البيانات والقياسات الخاصة بكل سباح. 2. إكتثاف الصعوبات أثناء إجراء القياسات لتحديد أفضل طريقة للقياس. 3. التأكد من صلاحية الأجهزة والأدوات المستخدمة في القياس والتدريبات المقترحة قيد البحث. 4. التأكد من مناسبة الأختبارت لأفراد عينة البحث. 5. ندريب المساعدين علي أساليب القياس المستخدمة في البحث وكيفية إجراء تلك القياسات وترتيبها.

6. التأكد من مناسبة الاحمال البدنية المستخدمة بالبرنامج لطبيعة لطبيعة المرحلة السنية.

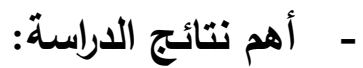
1. الكثف عن الصعوبات التي قد تواجه تطبيق البرنامج . 2. تدريب أفراد عينة البحث علي طريقة إستخدام الأجهزة والأدوات المستخدمة في البحث .

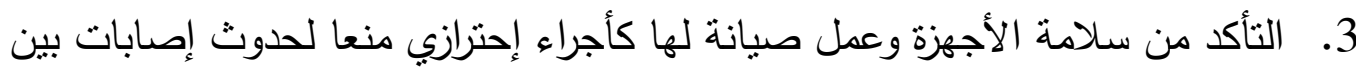

$$
\text { السباحين. }
$$

4. تم تدريب المساعدين علي أساليب القياس وكيفية إجراءها.

5. نم التأكد من مناسبة الأحمال لعينة البحث قيد الدراسة.

6. وضع جدول وترتيب مناسب لأجراء القياسات.

7. وضع تصميم أمن لتطبيق وحدات البرنامج التجريبي. 
تم إجراء القياسات القبلية لمجموعات البحث خلال الفترة من السبت الموافق 2019/10/13

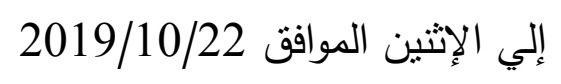

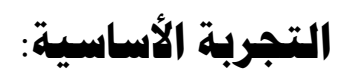

أجريت الدراسة الأساسية في الفترة من السبت الموافق ( 2019/11/2 ) حتي السبت

الموافق (2020/2/1)

\section{يمئم وتقنين هحتويات البرنامج التدريبي:}

قام الباحث بسمح للمراجع العلمية المتخصصة في مجال تدريب الكروس فيت والسباحة

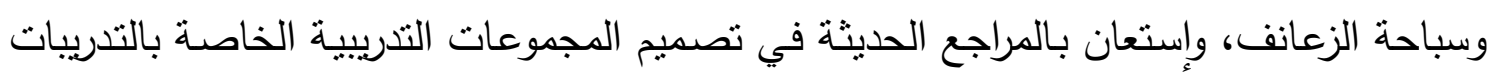

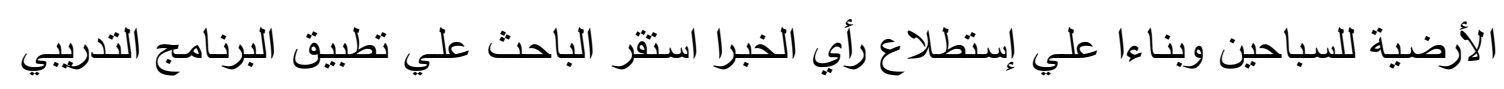

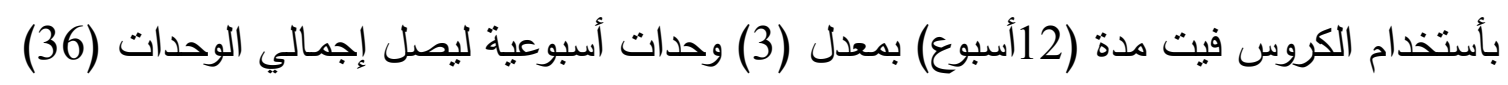

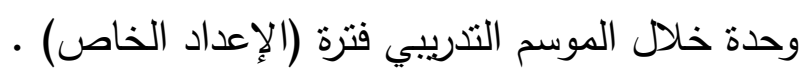

\section{ثانيا خطوات تصميم البرنامج التدريبي المتزرح:}

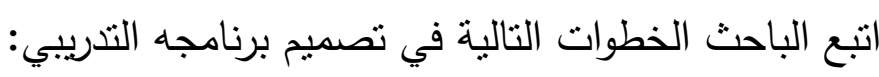

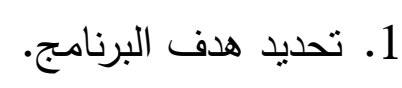

2. 2. تحديد بدء ونهاية الفتزة الزمنية للبرنامج.

3. إجراء الأختبارات والمقاييس لتحديد مستوي اللاعبين.

4. تحديد أسابيع فنترات بداية ووسط ونهاية البرنامج.

5. تحديد دورات الحمل والساعات التشربية وفقا لدرجة الحمل.

6. تحديد الزمن الكلي للتنريب وتوزيع الزمن علي الأعدادات المختلفة .

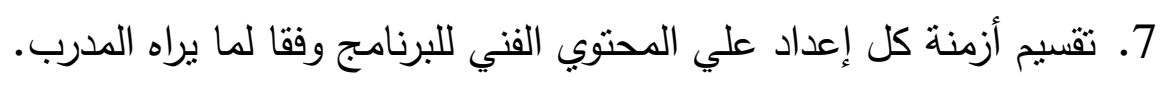

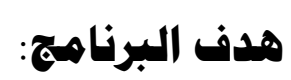

حدد الباحث هدف برنامجه التدريبي المقترح في محاوله لتطوير القدرات البندية والمستوي

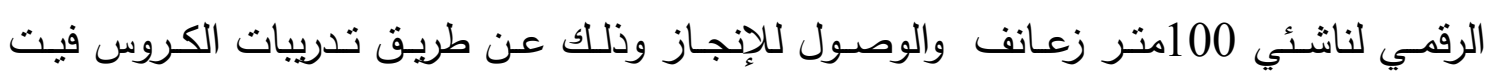
المقترحة. 


\section{الأسس العلمية التي تم هراعتها عند وضع البرناهج التدريبي:}

1. أن يحقق البرنامج الأهداف الموضوعة لتتمية عناصر اللياقة البدنية الخاصة والمستوي لئي

$$
\text { الرقمي للسباحين. }
$$

2. أن تتناسب محتويات البرنامج مع قدرات السباحين دون التعارض مع الحمل التدريبي 3. أن يكون تركيز التدريبات المقترحة علي المجموعات العضلية التي يحتاجها السباح خلال

$$
\text { الأداء وعلي جميع أجزاء الجسم. }
$$

4. تنويع محتويات البرنامج واتسامه بالمرونه.

5. مراعاة مبدأ تموج وتدرج الحمل التدريبي.

6. مراعاة تثكيل المناسب لحمل التدريب من حيث الثدة والحجم وفترات الراحة.

\section{هدددات البرناهمج التدريبي:}

حدد الباحث فترة تتفيذ برنامجه التدريبي المقترح (12) أسبوع تدريبي، وافترض أنها مناسبه

لتحقيق هدف بحثث، وذلك بواقع 3 وحدات تدريبية أسبوعيا.

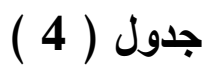

\begin{tabular}{|c|c|c|}
\hline الفترة & متغيرات البرنامج التّريبي & p \\
\hline 12 أسبوع & مدة البرنامج التّريبي & 1 \\
\hline 3 وحدات أسبوعية & عدد الوحدات اليومية في الأسبوع & 2 \\
\hline 120 & زمن الوحدة التدريبية & 3 \\
\hline 360 & الزمن الكلي في الأسبوع & 4 \\
\hline 4.320 & إجمالي زمن البرنامج & 5 \\
\hline 20\%من زمن الوحدة الكلي & زمن الأحماء & 6 \\
\hline 10 - مق & زمن التهئيه & 7 \\
\hline $1-2$ & دورة الحمل & 8 \\
\hline
\end{tabular}

محددات البرنامج التدريبي

التوزيع الزهني والنسبي لككونات البرناهج المترح:

جدول ( 5 ( )

\begin{tabular}{|c|c|c|}
\hline 2 أسـابيع & مرحلة الإعداد العام & 1 \\
\hline 10أسابيع & مرحلة الإعداد الخاص & 2 \\
\hline
\end{tabular}

توزيع مراحل الاعداد علي البرنامج 


$$
\text { جدول ( } 6 \text { ) }
$$

تثكيل حمل التدريب للبرنامج التدريبي المقترح

\begin{tabular}{|c|c|c|c|c|}
\hline \multirow{2}{*}{ الراحة } & \multicolumn{2}{|c|}{ الحجم } & \multirow{2}{*}{ الثدة } & \multirow{2}{*}{ الأسبوع } \\
\hline & $ت$ & مج & & \\
\hline$\doteq 20$ & 12 & 3 & $\% 65: 50$ & الأول \\
\hline$\$ 20$ & 12 & 3 & $\% 75: 70$ & الثاني \\
\hline$\$ 25$ & 12 & 3 & $\% 70: 65$ & الثالثة \\
\hline$\$ 25$ & 12 & 3 & $\% 80: 75$ & الرابع \\
\hline$\$ 30$ & 12 & 3 & $\% 85: 80$ & الخامس \\
\hline$\$ 30$ & 10 & 3 & $\% 75: 70$ & السادس \\
\hline$\$ 35$ & 10 & 3 & $\% 90: 85$ & السابع \\
\hline$ث 35$ & 10 & 3 & $\% 95: 90$ & الثامن \\
\hline$ث 35$ & 10 & 3 & $\% 80: 75$ & التاسع \\
\hline 340 & 10 & 3 & $\% 85: 80$ & العاثشر \\
\hline 340 & 8 & 3 & $\% 95: 90$ & الحادي عثر \\
\hline 340 & 8 & 2 & $\% 100: 95$ & الثاني عشر \\
\hline
\end{tabular}

تم تتفيذ البرنامج التدريبي خلال فترة الإعداد الخاص حيث إستخدت (المجموعة التجربية)

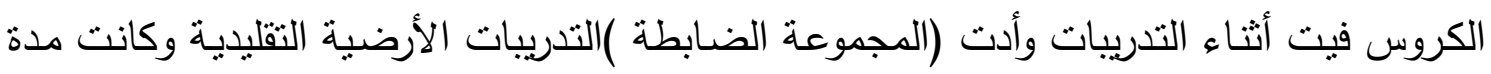

$$
\text { البرنامج (12أسبوع) بواقع ثناث وحدات في الأسبوع. }
$$

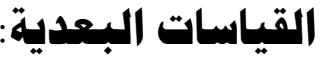

تم إجـراء القياسـات البعديـة لمجموعات البحث بعد إستكمال البرنـامج التـريبي ، وبنفس الطريقة التي تم بها تطبيق القياسات القبلة، وتحت نفس الظروف. بناريخ (2020/2/3)

استخدم الباحث الحزمة الإحصائية SPSS لحساب قيم المعاملات الإحصائية المستخدمة . Statistical Package For Social Science

$$
\text { 1. (Mean) المنوسط الحسابى) }
$$

2. (Median) الوسيط الونطابط

3. الانحراف المعيارى (Standard Deviation).

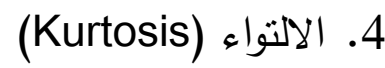

5. اختبار (ت) لعينتين مرنبطتين من البيانات (Paired Sample t-Test). 6. اختبار (ت) لعينتين مستقلنتين من البيانات (Independent Samples t-Test). 7. حجم التأثير (Effect Size) في حالة اختبار (ت): 


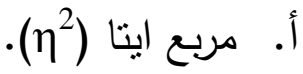

$$
\begin{aligned}
& \text { ب. باستخدام (ES) ويفسر طبقا لمحكات كوهين. }
\end{aligned}
$$

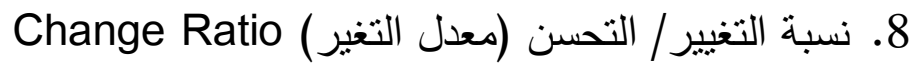

$$
\begin{aligned}
& 100 \times \\
& \text { القياس البعدى - القياس القبلى }
\end{aligned}
$$

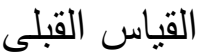

$$
\begin{aligned}
& \text { نسبة التحسن }
\end{aligned}
$$

عرض وهناقشة النتائج

يتتاول هذا الفصل نتائج التحليل الإحصائي، وذلك بهدف اختبار صحة الفروض، ومناقثة

النتائج وتفسرها، وفيما يلي عرض تفصيلي لنتائج الدراسة ومناقشتها: - - مرض ومناقثة نتائج الفرض الأول:

$$
\text { - - التحقق من صحة الفرض الأول: }
$$

ينص الفرض الأول على أنه :" توجد فروق دالة إحصائيًا بين القياسين القبلي والبعدي (المجموعة التجريبيـة) في المتغيرات قيد البحث لصالح القياس البعدي"؛ وللتحقق من صحة Paired Sample ) الفرض الأول استخدم الباحث اختبار (ت) لعينتين مرتبطتين من البيانات

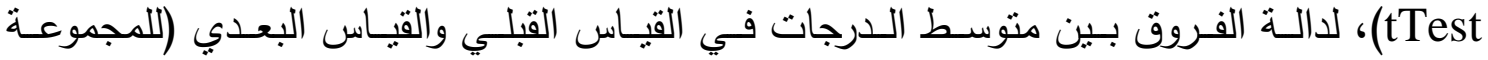
التجريبية)، في المتغيرات قيد البحث، كما تم حساب حجم التأثير (Effect Size) باستخدام مربع ايتا (2) في حالة اختبار (ت)، كما تم حساب حجم التأثثر باستخدام (ES) ويفسر طبقا لمحكات

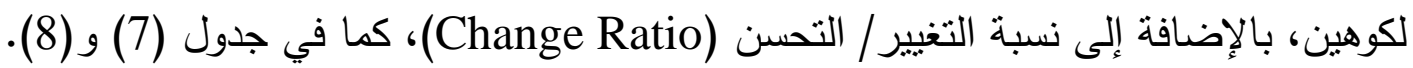
جدول (7) جندو)

\begin{tabular}{|c|c|c|c|c|c|c|c|c|}
\hline \multicolumn{2}{|c|}{ حجم التأثير } & \multirow{2}{*}{ قتيمة } & \multicolumn{2}{|c|}{ القياس البعدي } & \multicolumn{2}{|c|}{ القياس القبلي } & \multirow{2}{*}{ والقياس } & \multirow[b]{2}{*}{ الاختبارت } \\
\hline (ES) & $\left(n^{2}\right)$ & & 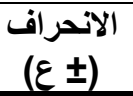 & أمتوسط) & 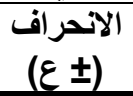 & المتوسط) & & \\
\hline 2.3 & 0.828 & 6.58 & 1.64 & 13.30 & 1.87 & 9.20 & سم & مرونة العمود الفقري في المد \\
\hline 2.9 & 0.960 & 14.71 & 3.69 & 26.40 & 2.69 & 16.10 & عدد & القوة العضلية للأراعين \\
\hline 3.7 & 0.942 & 12.13 & 4.99 & 60.00 & 3.57 & 43.60 & عدد & القوة العضلية للبطن \\
\hline 5.3 & 0.985 & 24.05 & 1.83 & $\begin{array}{c}249.3 \\
5\end{array}$ & 1.55 & $\begin{array}{c}240.2 \\
0\end{array}$ & 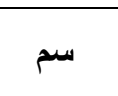 & القريض من الوقوفة الوثب \\
\hline 1.1 & 0.379 & 2.34 & 0.16 & 3.28 & 0.49 & 3.67 & $\dot{ث}$ & السرعة القصوي عدو30متر \\
\hline 2.2 & 0.956 & 14.01 & 2.31 & 32.00 & 2.58 & 22.00 & كجم & 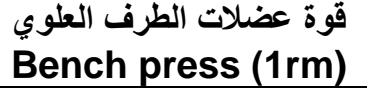 \\
\hline 3.2 & 0.967 & 16.16 & 4.74 & 43.50 & 3.94 & 29.00 & 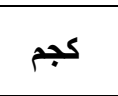 & قُوة عضلات الطرف السفلي \\
\hline
\end{tabular}

دلالة الفروق بين القياس القبلى والبعدى (للمجموعة التجريبية) في المتغيرات قيد البحث. $(10=\dot{0})$ 
- اكتمال البرنامج المقترح لمدة (12 أسبوع) المتضمن لتدريبات الكروس فيت مع تتوع طرق أدائها وكذلك طبيعة تتفيذ هذه التدريبات والمطبق على المجموعة التجريبية بمفردها دون المجموعة الضابطة. - - إتباع الأسـاليب العلمية في تقنين الأحمال من حيث (الثدة - الحجم - الكثافة) ومراعاة

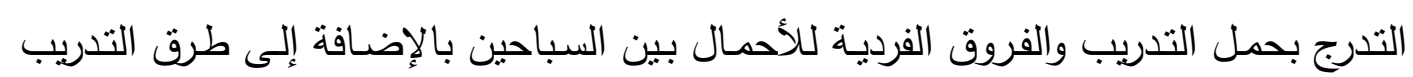
المستخدمة. - دقة اختيـار التـريبات الخاصـة بـالكروس فيت مـع مراعـاة المرحلـة العمريـة داخل البرنـامج التدريبي المقترح بشدات وتكرارات وراحات بينيـة ملائمـة، ممـا إنعكس على تتميـة القدرات البدنية قيد البحث. حيث يشير "فابيو دمونسكي"وأخرون Fàbio Dominski (2020) أن الكروس فيت

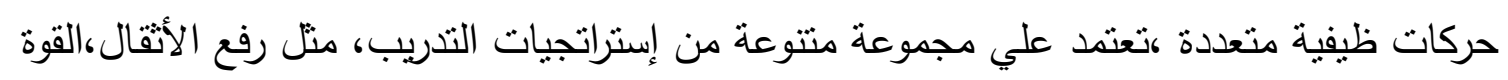

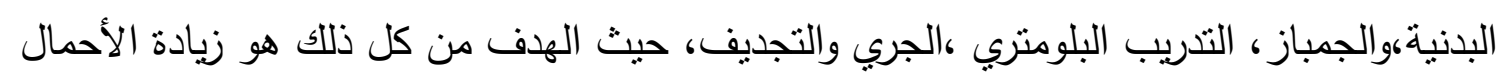
من حيث الحجم والثدة لتحسين الأداء ـ (4.19) كما تشير نتائج جدول (8) إلي وجود نسبة تحسن بين القياسات القبلية والبعدية للمجموعة

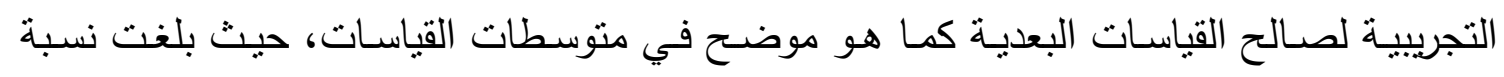
التحسن القدرات البدنية في إختبارات تحمل قوة الذراعين (63.98)، وتحمل قوة البطن (37.61) ،

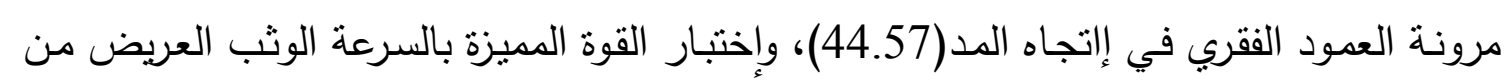

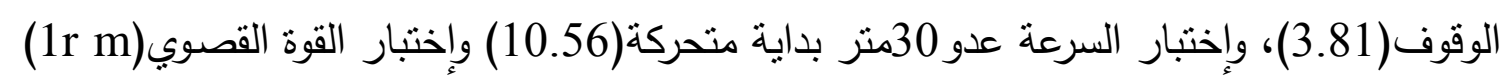

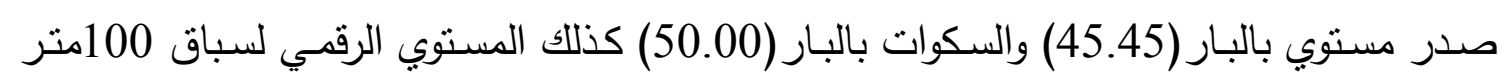
زعانف (4.41)

ويعزي الباحث حدوث تحسن في القوة العضلية للجذع والرجلين والذراعين، والقوة القصوي

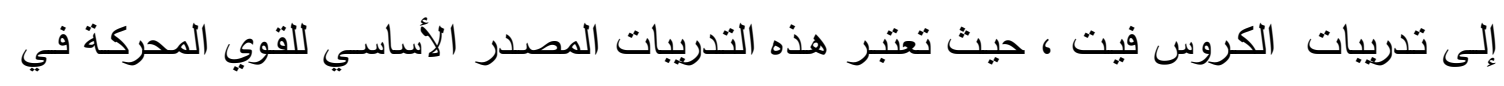
السباحة باستخدام الزعانف الأحادية، حيث يؤكد طارق مهدي عطية 2012م أن العضد العضلات العاملة

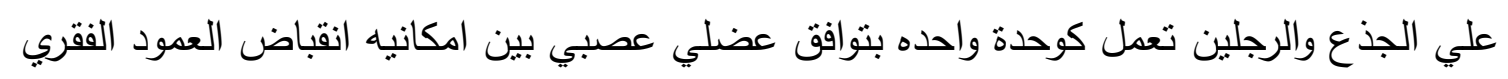

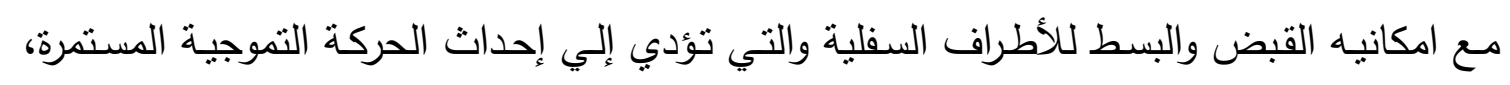
الأمر الذي يتطلب زيادة تتميه مرونة هذا الجزء لسباحي الزعانف. (74: 
وهذا يتفق ايضـا مـع ما ذكره محمد القط (2002م) في أنه لتتمية القوة القصوى للسباحين يستخدم التدريبات البدنيـة ويستخدم في ذلك أثنكال متتوعـة مـن التدريب مثنل تدريبات الأثقال والتدريبات الأيزوكينتيكة والبليومنرية ـ (17.11)

كما يعزي الباحث حدوث تحسن في المرونـة العمود الفقري في إتجاه المد إلي إستخدام

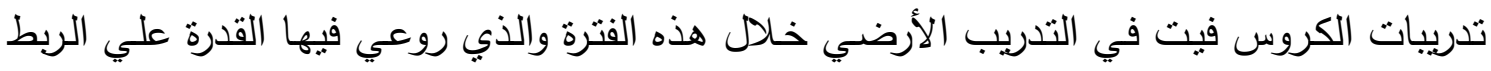

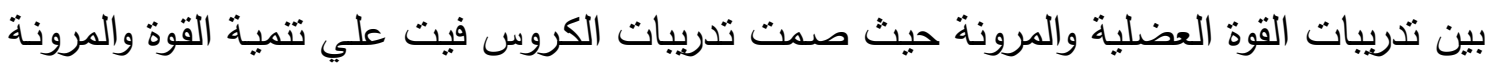

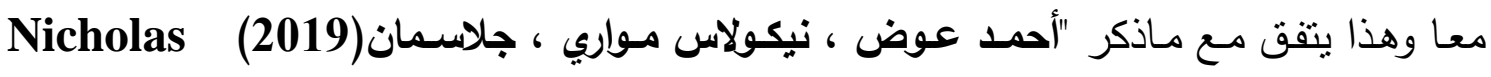
Murray \& Glassman بين التمارين الوظيفية والأوازان المجزئة ونطاق الحركة وتدريبات القدرة ومساراتها والمرونـة والسرعة لئه وجميع عمليات الأيض ذات الصلة في قيمة واحدة لذا فأن الكروس فيت رياضة الكة اللياقة البدنية.

كما يعزي الباحث حدوث تحسن في القدرة العضلية للرجلين، إلى تدريبات الكروس فيت،

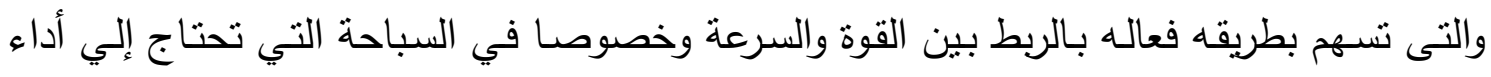

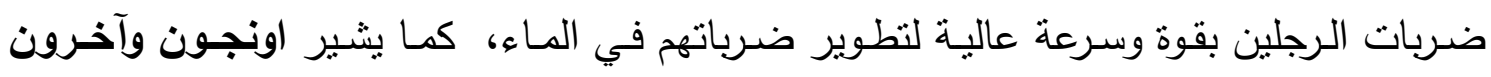
2013م Ongun

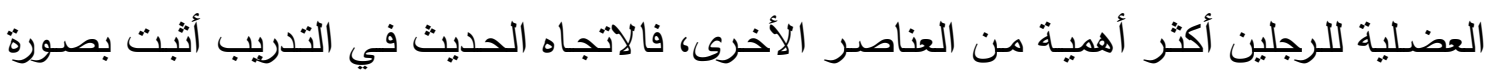

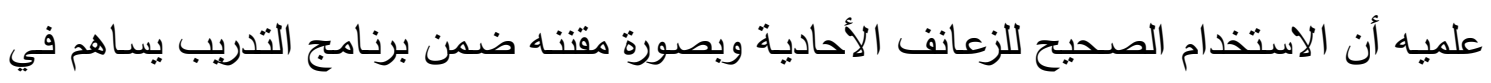
إنتاج القوة السريعة للرجلين. (22 : 55) ويعزي الباحث حدوث تحسن في السرعة القصوي كذلك في المستوي الرقمي لسباحة 100منز زعانف إلي تدريبات الكروس فيت وبما تحتوية من تدريبات روعي فيها الربط بين الأنشطة الهوائية

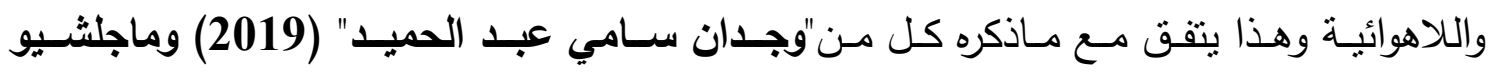

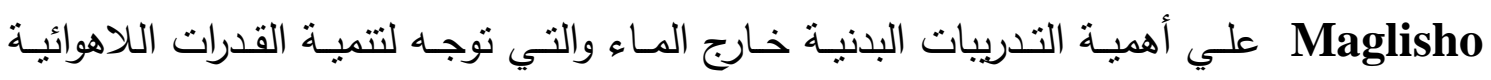

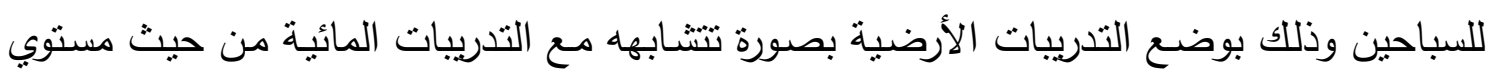
الثدة المستخدمة بهدف تحقيق التتمية الثامله والوصول لأعلي تكيف للتنريب. (6.17)

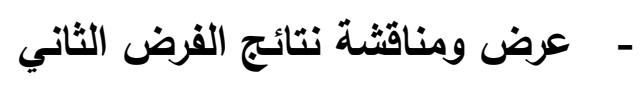
- - مرض نتائج الفرض الثاني ينص الفرض الثاني على أنه :" توجد فروق دالة إحصائيًا بين القياسين القبلي والبعدي

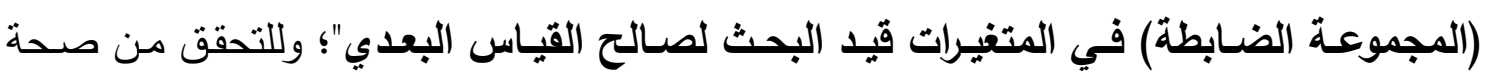


Paired Sample ) الفرض الثاني استخدم الباحث اختبار (ت) لعينتين مرتبطتين من البيانات

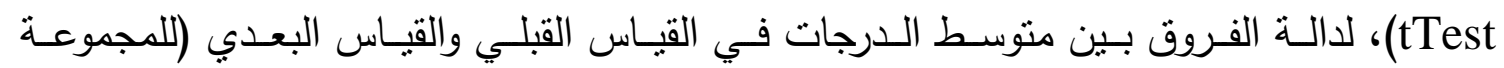

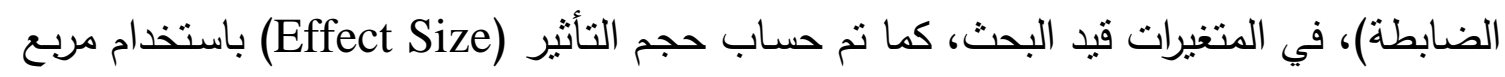

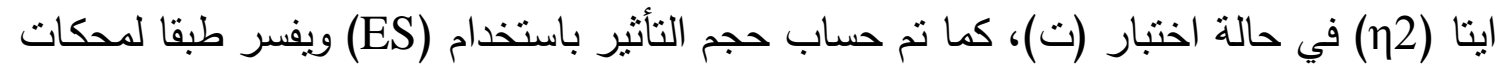

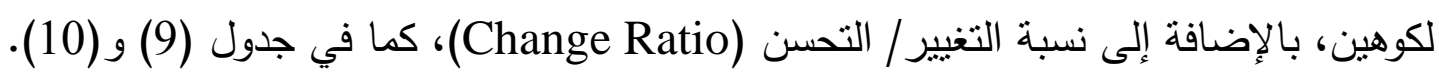

جدول (9)

دلالة الفروق بين القياس القبلى والقياس البعدى (للمجموعة الضابطة) في المتغيرات قيد البحث. $(10=0)$

\begin{tabular}{|c|c|c|c|c|c|c|c|c|}
\hline \multicolumn{2}{|c|}{ حجم التأثير } & \multirow{2}{*}{ قيمة } & \multicolumn{2}{|c|}{ القياس البعدي } & \multicolumn{2}{|c|}{ القياس القبلي } & \multirow{2}{*}{ القياس } & \multirow[b]{2}{*}{ الاختبارت } \\
\hline (ES) & $\left(\eta^{2}\right)$ & & $\begin{array}{l}\text { الاتحراف) } \\
\text { (ع } 1 \text { ) }\end{array}$ & 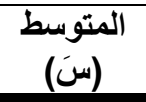 & 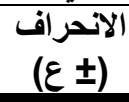 & $\begin{array}{c}\text { المتوسن) } \\
\text { (سن) }\end{array}$ & & \\
\hline 1.8 & 0.906 & 9.30 & 2.91 & 21.00 & 2.49 & 16.00 & عدد & القوة العضلية للأراعين \\
\hline 1.6 & 0.737 & 5.02 & 4.94 & 51.20 & 4.16 & 43.70 & عدد & القوة العضلية للبطن \\
\hline 0.1 & 0.100 & 1.00 & 2.00 & 9.35 & 2.13 & 9.10 & 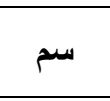 & مرونة العمود الفقري في \\
\hline 1.1 & 0.581 & 3.53 & 3.37 & 245.40 & 2.69 & 241.90 & سم & العريض العنلية الوقثب \\
\hline 0.1 & 0.609 & 3.75 & 0.34 & 3.64 & 0.34 & 3.68 & ث & السرعة القصوي عدو 30متز \\
\hline 2.8 & 0.900 & 9.00 & 2.58 & 27.00 & 1.70 & 20.70 & 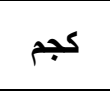 & قوة عضلات الطرف العلوي \\
\hline 1.5 & 0.579 & 3.52 & 4.38 & 34.50 & 4.61 & 27.80 & 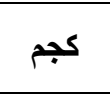 & قوة عضلات الطرف السفلي (1rm) سكوات بالبر \\
\hline 0.4 & 0.116 & 1.09 & 1.07 & 50.80 & 1.63 & 51.41 & 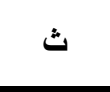 & المستوي الرقمي 100متر \\
\hline
\end{tabular}

$$
\text { يتضح من جدول (9) أن قيم (ت) المحسوبة تراوحت بين (1.00) و (9.30). }
$$

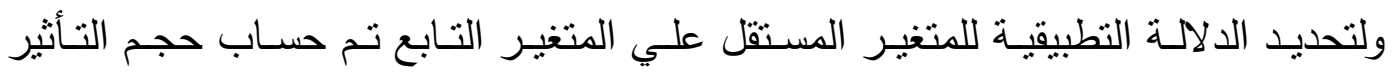

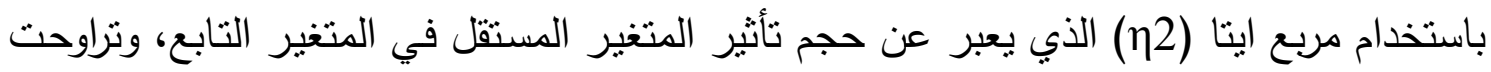

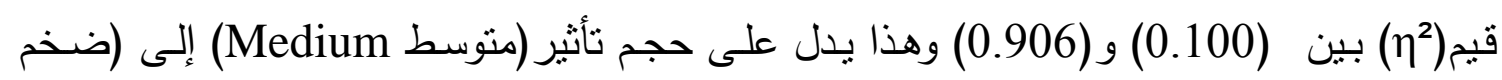
.(Huge

وتراوحت قيم(ES) بين (0.1) و (2.0) وهذا بدل على حجم تأثير (منعدم) إلى (ضخم

.(Huge 


\section{جدول (10) (10)}

نسبة التحسن بين درجات (المجموعة الضابطة) في المتغيرات قيل البحث.

\section{$(\mathbf{1 0}=\dot{0})$}

\begin{tabular}{|c|c|c|c|c|c|}
\hline التحسبة & القرق بين & متوسط القياس & القياس القبلي & القياس & الاختبار ات \\
\hline 31.25 & 5.00 & 21.00 & 16.00 & عدد & القوة العضلية للأراعين \\
\hline 17.16 & 7.50 & 51.20 & 43.70 & عدد & القوة العضلية للبطن \\
\hline 2.75 & 0.25 & 9.35 & 9.10 & سم & مرونة العمود الفقري في اتجاه المد \\
\hline 1.45 & 3.50 & 245.40 & 241.90 & سم & القدرة العضلية الوثب العريض من الوقوف \\
\hline 0.95 & 0.03 & 3.64 & 3.68 & 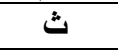 & السر عة القصوي عدو 30متر \\
\hline 30.43 & 6.30 & 27.00 & 20.70 & كجم & قوة عضلات الطرف العلوي (1rm ) \\
\hline 24.10 & 6.70 & 34.50 & 27.80 & كجم & قوة عضلات الطرف السفلي (1rm) \\
\hline 1.18 & 0.61 & 50.80 & 51.41 & $\dot{H}$ & المستوي الرقمي 100متر زعانف \\
\hline
\end{tabular}

يتضح من جدول (10) أن قيم (نسبة التحسن) تراوحت بين (1.18) و (31.25)

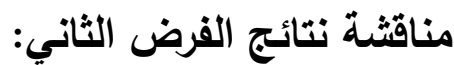

يتضح من جدول(10) توجد فروق دالة إحصائية بين القياس (القبلي - البعدي) للمجموعة

الضابطة في القدرات البدني الخاصة لسباحي الزعانف لصالح القياس البعدي ، وتراوحت قيم(证

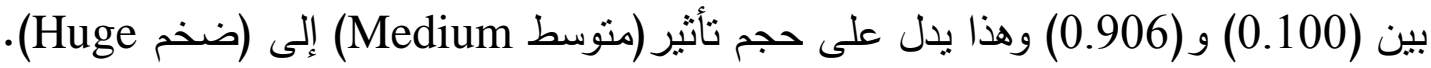

ويتضح من جدول (10) أن نسب التحسن في القدرات البدنية والمستوي الرقمي تراوحت

$$
\text { بين(1.18) و (31.25) • }
$$

كما تشير نتائج جدول(10) وجود نسبة تحسن بين القياسـات القبلية والبعديـة للمجموعـة الضـابطة لصـالح القياسـات البعديـة كما هو موضح من منوسطات القياسـات، حيث بلغت نسبة تحسن تحمل قوة الذراعين (31.25) تحمل قوة البطن (17.16)، وإختبار مرونة العمود الفقري في إتجاه المد (2.75) ، والقدرة العضلية للرجلين إختبار الوثب العريض من الثبات(1.45)، والسرعة

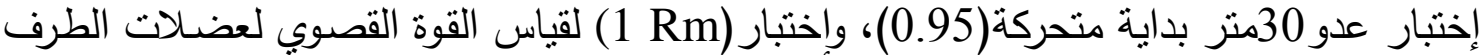
العلوي من خـلال إختبار الصدر المستوي بالبار (30.43)، وعضلات الطرف السفلي من خـلال إختبار السكوات بالبار (24.10) كذلك المستوي الرقمي من خلال سباق 100متر زعانف (1.18) ويعزي الباحث حدوث التحسن في القوة العضلية نتيجة لتأثير تدريبات القوة العضلية التي إحتواها البرنامج بنسب محددة في خلال هذه الفترة والتي روعي فيها مبادئ التدريب في خصوصية

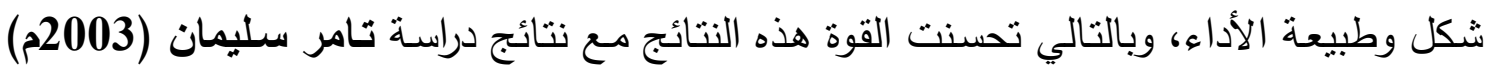
(7) ودراسة أوزمسون وآخرون (1994م) (23) في أن تدريبات القوة المشابهة للأداء وبإستخدام الأثقال تؤثر إيجابيا علي القدرة للذراعين والرجلين. 
ويعزي الباحث حدوث تحسن في مرونة العمود الفقري في إتجاه المد إلي استخدام التدريبات

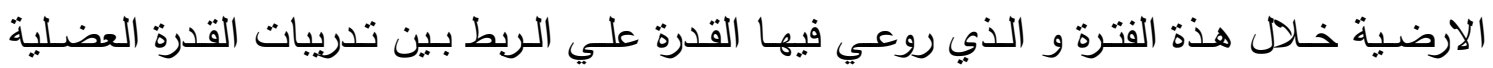

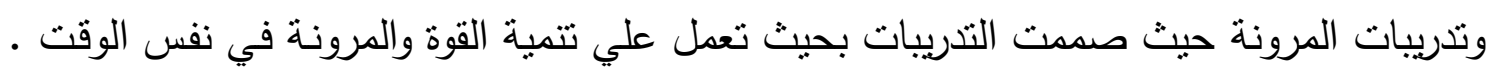

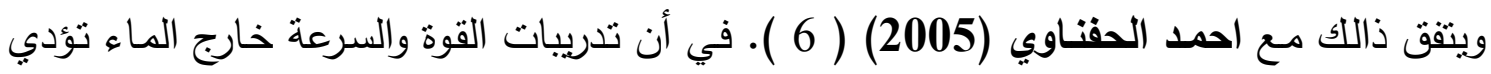
إلى تتمية القوة العضلية والمرونة.

ويعزي الباحث حدوث تحسن في القدرة العضلية نتيجة بعض تدريبات القوة والسرعة التي ولي إحتواها البرنامج وهذا يتفق مع ماذكره أحمد خاطر وعلى البيك (1996) أن القوة المميزة بالسرعة

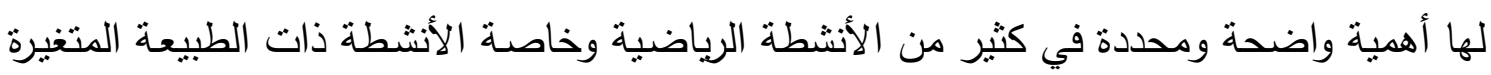
من حيث الأداء الحركي والتي تحتاج إلى القدرة على الانقباض في اللحظة المناسبة. (3: 266)

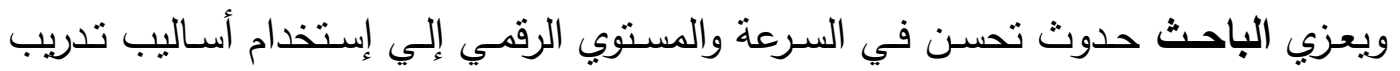

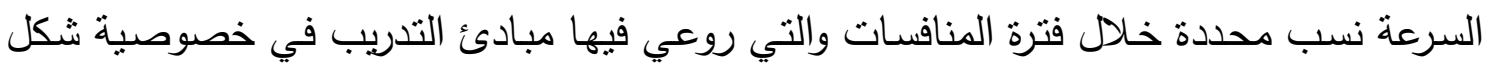
وطبيعة الأداء،ويتفق ذلك مع ما ذكره ماجليشو (2003م) أن تدريبات تحمل اللاكتياك من تأثيراتها

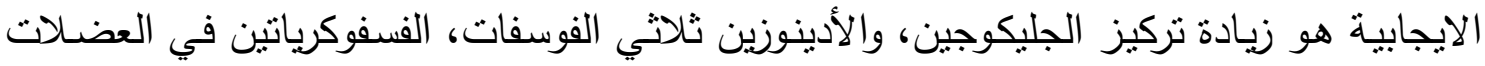

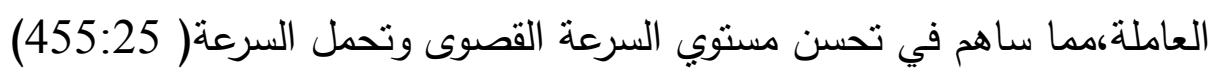

الأستنتاجات:

من خلال الأهداف والفروق التي وضعت للبحث وفي حدود عينـة البحث والمنهج المستخدم والاختبارات والقياسـات المطبقة ، ومن خـلال المعالجات الاحصـائية التي استخدمت في في عرضه

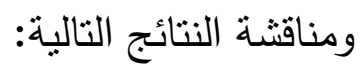
1. أثر البرنـامج المقترح تأثثرا ايجابيـا في تطوير بعض القدرات البدنيـة الخاصـة بسباحة الزعانف. 2. أثر البرنامج التدريبي المقترح تأثثرا ايجابيا في تطوير وتحسين المستوي الرقمي لسباحة الزعانف.

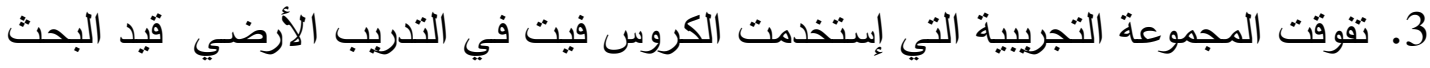

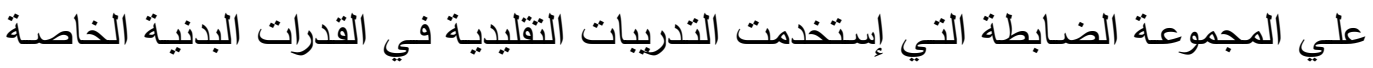
والمستوي الرقمي لسباحة الزعانف.

إستتادا إلي النتائج والاستخلاصـات الني توصل إليها الباحث من خلال هذا البحث يوصي الباحث بمايلي: 
1. ضرورة الاهتمام من قبل العاملين في المجال العلمي التطبيقي بأستخدام تدريبات الكروس

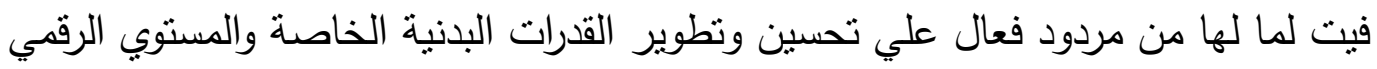
لسباحة الزعانف.

2. اجراء دراسات مشابهه تنتاول مراحل سنية أخري لتحديد ثأثثر تدريبات الكروس فيت مقارنة بتأثير تدريبات الأرضي التقليدية لاي السباحين والسباحات.

قائمة المراجع

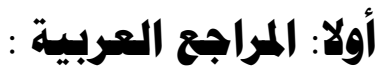

1. أحمد عوض حسن (2019م) "تأثثر تدريبات الكروس فيت علي التحمل العضلي

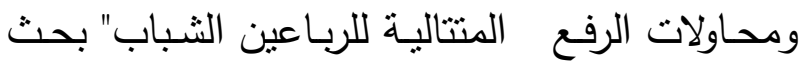

منشور كلية التربية الرياضية جامعة دمياط.

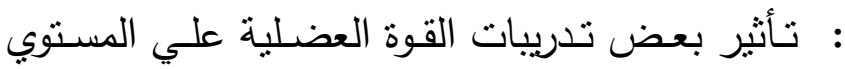

2. أثرف محمد جمعة

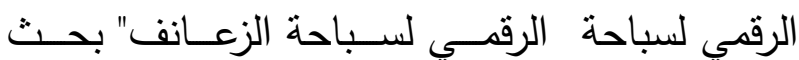

(2019)

منشور كلية التربية الرياضية جامعة المنصورة.

3. أحمد محمد خاطر،علي البيك القيـاس في المجـال الرياضـي، الطبعـة الرابعـة،دار

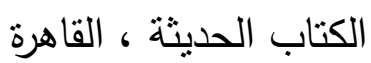

(1996)

ا

4. - أبو العلا أحمد عبد

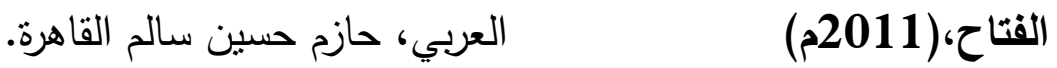

5. أبوالعلا عبدالفتاح (1994م) : تدريب السباحة للمستويات العليا، دار الفكر العربي،

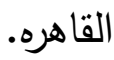

: تأثنير تدريبات القوة والسرعة علي المستوي الرقمي

6. - أحمد أمين الحفناوي

لسباحي الفراثة رسالة ماجستير غير منشورة ، كلية

(2005)

التربية الرياضة جامعة طنطا.

: تتمية تحمل القوة وعلاقتة بالمستوى الرقمى للسباحين

7. امر عبدالله سليمان

النانشئي" رسالة ماجستير غير منشورة كلية التربيـة

(2003)

الرياضية جامعة الزقازيق.

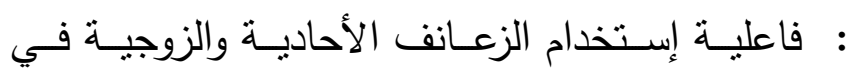

8. طارق مهدي عطية

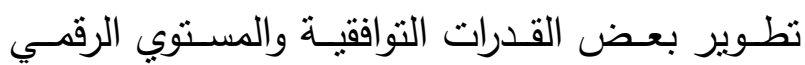

(2012) 
لسـباحي الفراثــة الناثــئين دراسـة مقارنــة، المجلــة

العلمية لكلية التربية الرياضية للانين جامعة حلوان.

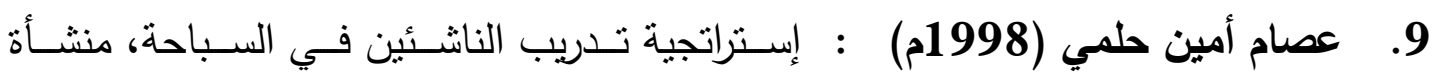

$$
\text { المعارف، إسكندرية }
$$

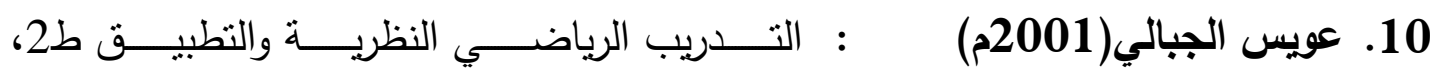
دار G.M.S - للطباعة، القاهرة.

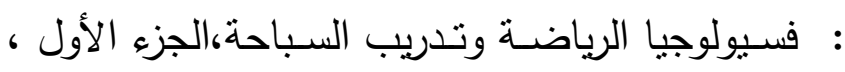

11. محمد علي القط (2002) المركز العربي للنشر، القاهرة.

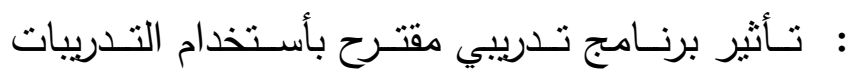

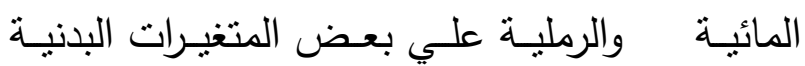
12. - 12 محمد محمود عبد التواب

(2016)

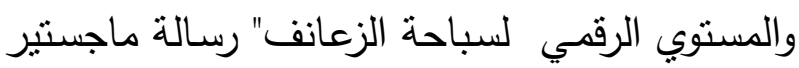
غير منشورة كلية التربية الرياضية جامعة المنيا. : محاضـرات فـي التـدريب الرياضـي، كليـة التربيـة الرياضية جامعة المنصورة.

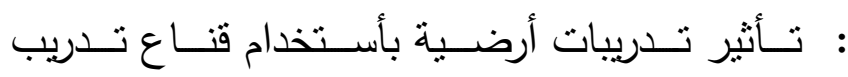

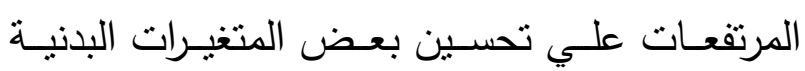

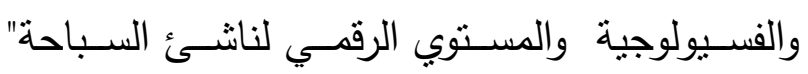

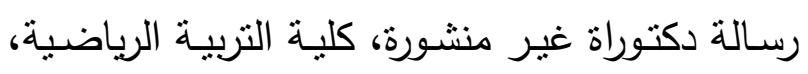
جامعة إسكندرية.

15. مصطفي عبد الناصر حسين فاعليـة برنــامج تـدريبي مقترح للأرتقـاء بالمسـتوي الرقمـي لسـباحة الزعـانف" رسـالة ماجسـتير غيـر منشورة، كلية التربية الرياضية، جامعة المنيا ـ

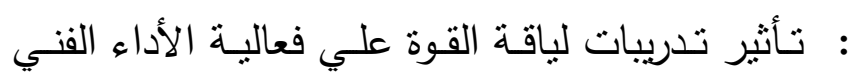
16. نوره أبو المعاطي فرج

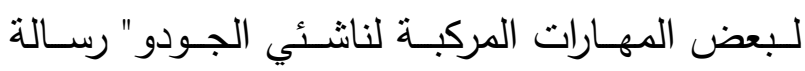
(2012) ماجستير غير منشورة ، كلية التربية الرياضية جامعة المنصورة. : تأثثر تدريبات الكروس فيت علي بعض المتغيرات 13. محمد شوقي كثك، أمرالله (البساطي (2001م) 14. مصطفي سمير عبد الجواد (2018م) 
الفسيولوجية والمستوي الرقمي لسباحي 400متر حرة

(2019)

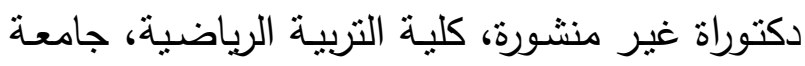

بني سويف.

: : كتاب دوري يصدر عن الإتحاد الدصري للغوص

18. قواعد السباحة بالزعانف

والانقاذ.

بالأتحاد الاولي للغوص

(2017)

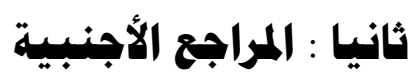

19. Fábio Dominski, : Motivation to CrossFit training Thiago anarrative review" Founded by the

Matias(2020) Faculty of Exercise Science University of Milan, official journal of the Italian Society of Exercise and Sport Sciences ISSN 1824-7490.

20. Nicholas Murray, : Vertical jump height as an indicator of You Fu (2019) lower-extremity muscular fatigue in recreational Crossfit athletes " University of Nevada, Reno1316713-1.

21. Moritz

Schumann, BentR.Ronstad (2019)

22. Ongun, M(2013)

Akm : The Effects of Hand Paddles and Fins on Speed and Stroke Frequency in Freestyle Swimming, Ege University, Physical Education and Sports School, Bornova, Izmir/Turkey.

23. Ozmun,D.C. : Neuromuscular adaptation follwing Mikesky,A.E. nd peepuce descent training" Medicine and Surbury,R. (1994) science in sport and exercise , India polishin,26:pp.,510-514,.Wilmore ,J.H. Costill ,D.L. (1994) : physiology of Sport And Exercise, Human Kinetics Champaign ,USA.

24. Ernest

W. : Swimming Fastest, Magfill publishing 
Maglischo (2003) co, California U.S.A .

25. Greag Glassman : The crossfit traning guide traning" (2002) DV2.3_20151204KW CrossFit is a registered trademark.

|لمستخلص

من خلال العرض والبحث المرجعي لبعض البحوث والمراجع العلمية والمقابلات الثخصية لمدربي السباحة واللياقـة البدنيـة للمراحل العمريـة المختلفة وعمل الباحث في مجال مجال اللياقـة البدنية والاعداد البدني للسباحين والبحث الدائم علي شبكة المعلومات الدولية (internet) لاحظ الباحث إفتقار برامج التدربب الأرضـي إلي وسائل تتمية القوة العضلية إلي جانب إستخدام برامج التدريب الأرضـي التقليديـة ولكن في ظل التطور العلمي في مجال الرياضـة والعلوم البدنيـة إلي

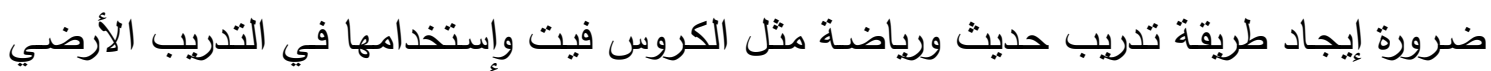
لسباحة الزعانف من أجل عمل نقلة نوعية في التدريب الأرضي لهذه السباحة التي بدأت تتنتر حديثا ومحاولـة الوصسول بالسباحين لأعلي مستويات اللياقة البدنيـة والمستوي الرقمي لذلك وجد الباحث أن سباحة الزعانف ورياضـة الكروس فيت تحتاج إلي المزيد من الدراسـة والبحث العلمي، وهذا مادفع الباحث إلي إجراء هذه الدراسة من أجل التعرف علي " تأثير تدريبات الكروس فيت علي بعض القدرات البدنية و المستوي الرقمـي لسباحي الزعانف" ، وقد إستخدم الباحث المنهج التجريبي وذلك بأستخدام مجموعتين احداهما تجربية والأخري ضـابطة مع إجراء القياسات القبلية والبعدية وقد تم إختيار عينة البحث والدراسة بالطربقة العمدية من القربة الأوليمبية جامعة المنصورة (25) سباحا من ناشئي الزعانف (16-17) المسجلين بالأتحاد المصري للغوص والإنقاذ وكانت أهم النتائج أن البرنامج التريبي المقترح له تأثيرا ايجابيا في تطوير القوة العضلية كما أن البرنامج التدريبي المقترح اثز تأثثرا ايجابيا في تطوير وتحسين المستوي الرقمي لسباق 100مترزعانف ، كما اظهرت النتائج تفوقت المجموعة التجريبية علي المجموعة الضـابطة في القوة العضلية قيد البحث وكذلك المستوي الرقمي لسباحة الزعانف. 


\begin{abstract}
Through the presentation and reference search of some research and scientific references and personal interviews of swimming and fitness coaches for different age groups, the researcher's work in the field of physical fitness and physical preparation for swimmers and permanent research on the international information network (internet), the researcher noticed the lack of ground training programs for the means of developing muscle strength besides The use of traditional ground training programs, but in light of the scientific development in the field of sport and physical sciences, the necessity of finding a modern training method and a sport such as Crossfit and using it in ground training for fin swimming in order to make a qualitative leap in ground training for this swimming that began to spread recently and try to reach swimmers to the highest levels Physical fitness and the digital level. Therefore, the researcher found that fin swimming and Crossfit sport need more study and scientific research, and this prompted the researcher to conduct this study in order to identify "the effect of crossfit training on some physical abilities and the digital level of fin swimmers." The researcher uses the experimental method by using two groups, one experimental and the other control With pre- and postmeasurements, the research and study sample was deliberately chosen from the Olympic Village, Mansoura University, (25) swimmers from the fin beginners (16-17) registered with the Egyptian Federation for Diving and Rescue, and the most important results were that the proposed training program has a positive effect in developing muscle strength as well. The proposed training program had a positive effect on the development and improvement of the digital level of the 100 fins race, and the results showed that the experimental group outperformed the control group in muscle strength under study as well as the digital level of fin swimming
\end{abstract}

